\title{
Mothers, Men, and Child Protective Services Involvement
}

\author{
Lawrence M. Berger, \\ University of Wisconsin-Madison \\ Christina Paxson, and \\ Princeton University \\ Jane Waldfogel \\ Columbia University
}

\begin{abstract}
This study used data on 2,297 families from the Fragile Families and Child Wellbeing Study to examine whether Child Protective Services (CPS) involvement varies by maternal relationship status. Families were categorized according to whether the mother was living with a (male) partner or spouse, was involved in a dating relationship, or was not romantically involved. Families in which the mother was romantically involved were further delineated by whether her partner was the biological father of none, some, or all of the children in her household. Results indicated that families in which the mother was living with a man who was not the biological father of all children and those in which she was not romantically involved were significantly more likely to be contacted by CPS than those in which she was living with the biological father of all resident children. These findings withstood the inclusion of detailed controls for the mother's characteristics and behaviors and (in two-parent families) her partner's characteristics and behaviors, suggesting that they are not fully explained by observable social selection factors.
\end{abstract}

\section{Keywords}

fathers; family relationships; child welfare; services/child protection

\begin{abstract}
Out-of-wedlock childbearing and parental cohabitation, divorce, and remarriage are common aspects of family life. As a consequence, a considerable portion of U.S. children live in families that do not include their biological fathers, but instead include "social fathers," defined here as stepfathers or unrelated cohabiting romantic partners of their mothers. It is estimated that about a third of children will, at some point during childhood, live with a social parent, most often a social father (Bumpass, Raley, \& Sweet, 1995). High rates of union dissolution and formation also imply that children are likely to come into contact with men their mothers date. Most single mothers engage in romantic dating relationships and many eventually cohabit or (re)marry (Furstenberg, Brooks-Gunn, \& Morgan, 1987; Osborne \& McLanahan, 2007).
\end{abstract}

The absence of biological fathers and the consequent presence of unrelated men may place children at risk of maltreatment. A substantial body of research suggests that a child is more likely to be maltreated if he/she lives with a social father than with his/her biological father; mothers' nonresident boyfriends are also thought to elevate maltreatment risk (Coohey \& Zhang, 2006; Daly \& Wilson, 1985, 1988; Lightcap, Kurland, \& Burgess, 1982; Margolin, 1992; Radhakrishna, Bou-Saada, Hunter, Catellier, \& Kotch, 2001; Schnitzer \& Ewigman, 
2005; Stiffman, Schnitzer, Adam, Kruse, \& Ewigman, 2002; Wilson \& Daly, 1987). The view that unrelated men are risky is widely enough accepted to be reflected in training materials for Child Protective Services (CPS) workers. For example, a U.S. Department of Health and Human Services manual on fathers and child maltreatment notes that, while the majority of unrelated men are not dangerous to children, "unrelated male figures and stepfathers in households tend to be more abusive than biological, married fathers" (Rosenberg \& Wilcox, 2006, p. 7) and that mothers' boyfriends pose risks because they "do not have the same history of care and nurturing with the child, the same emotional and normative commitment to the child's welfare, and the same institutionalized role as a father figure as do biological fathers" ( $p$. $35)$.

Although the view that social fathers and mothers' boyfriends pose maltreatment risk is widelyheld, the evidence to support this view has several shortcomings (Adler-Baeder, 2006). One is that research is hampered by data limitations. Many studies use administrative data to examine whether, relative to their representation in the population, families with stepparents are overrepresented in CPS rolls (Daly \& Wilson, 1985, 1988; Wilson \& Daly, 1987) or among child injuries or deaths (Daly \& Wilson, 1988). Although these studies are useful, they cannot provide information on why families with step-parents may be overrepresented. Other studies are based on samples of families selected because of current or previous CPS involvement (Coohey \& Zhang, 2006; Lightcap et al., 1982; Malkin \& Lamb, 1994), risk of maltreatment (Radhakrishna et al., 2001), or having experienced a child death at the hands of (step)parents (Schnitzer \& Ewigman, 2005; Stiffman et al., 2002). Population-based studies are more likely to provide accurate estimates of the effects of family structure on child maltreatment.

Another concern is that most previous studies have not accounted for selection factors that may explain the overrepresentation of families with social fathers or nonresident boyfriends among CPS cases, relative to two-biological-parent families. The presence of unrelated men may be correlated with a host of factors, such as lower levels of education, employment, or income, which themselves may drive higher rates of CPS involvement. Similarly, mothers who select into romantic relationships with men who are not related to their children may, on average, be more likely than other mothers to maltreat their children and/or to come to the attention of CPS. If so, then the unrelated men may not themselves be responsible for higher rates of maltreatment-implying that the removal of these men from children's lives may not reduce maltreatment risk.

Finally, despite the widespread belief that mothers' noncohabiting boyfriends pose maltreatment risk, there is little empirical evidence to support this effect. For example, Margolin (1992) focuses on maltreatment and mothers' boyfriends, but does not differentiate those who are dating from those who are cohabitating. The lack of evidence on this issue reflects the fact that few studies collect information on whether single mothers are involved in dating relationships.

This study examined whether children's exposure to unrelated men-both social fathers and men their mothers are dating - is associated with CPS involvement. We used data from the Fragile Families and Child Wellbeing Study (FFCW), a national cohort study that has tracked a sample of primarily low-income children from birth to age five. The data are well-suited for the topic. The interview conducted when focal children were approximately 5 years old contained questions about CPS involvement during the preceding 5 years; information on mothers' romantic relationships was used to assess whether coresident men and men that mothers were dating were biologically related to all, some, or none of the resident children. The survey also includes rich information on demographics and parenting behaviors, which we used to assess whether social selection drives the association between unrelated men and CPS involvement. 
Our analyses extend prior work in several important ways. First, we used a large and contemporary population-based sample to examine links between family type and CPS involvement. Second, we adjusted for a far wider range of selection factors than has been possible in prior studies. Third, we accounted for both coresident and dating relationships among children's mothers and their partners.

\section{Theoretical Framework}

There are several reasons CPS involvement might be related to a child's exposure to and involvement with unrelated men-either those who are married to or cohabiting with their mothers (called "social fathers"), or those dating their mothers (called "daters"). One view is that social fathers and daters will exhibit, on average, worse parenting behaviors than biological fathers: they will be less attached to the unrelated children of their romantic partners and less willing to invest in these children's care than are biological fathers with regard to their own children (Daly \& Wilson, 1980; Emlen, 1997). Although the behaviors of unrelated men may be modified by whether they also have biological children with a child's mother, as well as the degree of contact they have with a child, the essence of this view is that unrelated men place children at elevated risk of maltreatment. An alternative view is that social selection produces an association between maltreatment risk and children's exposure to social fathers or daters. That is, the presence of unrelated men may be correlated with other, often unobserved, factors that elevate maltreatment risk. We discuss these ideas in more detail, below.

\section{The Parenting Behaviors of Social Fathers}

Evolutionary perspectives on child rearing suggest that men's investments in children are largely influenced by genetic links such that biological fathers, because they have an evolutionary interest in passing on their genes and promoting their children's success, will make larger and higher quality investments in children than social fathers (Daly \& Wilson, 1980; Emlen, 1997). As such, biological fathers should also be less likely to abuse or neglect children (Daly \& Wilson, 1980; Malkin \& Lamb, 1994).

The family economics literature further suggests that parental investments in children will vary according to parents' expectations regarding future compensation for such investments, as well as their perceptions of children's endowments (see, e.g., Bergstrom, 1997; Case, Lin, \& McLanahan, 2000). Biological fathers likely expect that their relationships with their offspring will endure and that their children will care for them in old age; social fathers may not share these expectations. Biological children may also be perceived to have more favorable endowments than social children, perhaps because social children have suffered adverse psychological or other consequences as a result of earlier life experiences (Case et al., 2000), including the economic deprivation often encountered in single-mother families and the process of parental breakup and/or repartnering. Both of these factors suggest that biological fathers should make larger investments in and be less likely to maltreat children than social fathers.

Theories of the family as a social institution posit that biological fathers are both legally and socially obligated to invest in children, whereas social fathers have fewer such obligations (Cherlin, 1978; Cherlin \& Furstenberg, 1994; Furstenberg \& Cherlin, 1991). In addition, because social fathers face an ambiguously defined parental role and little institutionalized parenting authority with regard to their partner's children (Cherlin \& Furstenberg, 1994; Furstenberg \& Cherlin, 1991, Marsiglio, 2004), they may be less able to enforce rules or gain compliance from children, and some social fathers may resort to physical force to assert their power over children (Giles-Sims \& Finkelhor, 1984; Margolin, 1992). Furthermore, social father families may be "structurally predisposed for conflict" to the extent that social fathers 
and children compete for mothers' time, energy, attention, or affections (Margolin, 1992, p. 542).

Together, these perspectives suggest that biological fathers will make higher quality investments in children than social fathers and that social children should, therefore, have a higher probability of CPS involvement than biological children. Consistent with this hypothesis, the majority of existing empirical studies, although subject to the limitations discussed above, find positive associations between social father presence and child maltreatment (Coohey \& Zhang, 2006; Daly \& Wilson 1985, 1988; Lightcap et al., 1982; Margolin, 1992; Radhakrishna et al., 2001; Schnitzer \& Ewigman, 2005; Stiffman et al., 2002; Wilson \& Daly, 1987).

\section{Blended Families}

If social children should have a higher probability of experiencing maltreatment than biological children, it might follow that CPS involvement will increase with the proportion of children in a mother's household to whom her current partner is not biologically related. However, her partner's investments in social children may vary by whether he also has biological children with her. One possibility is that a social father will invest in a mother's children from previous relationships as a form of "mating" or "relationship effort." This effort may increase the likelihood of an ongoing relationship with the mother, potentially resulting in the birth of new children (Anderson, Kaplan, \& Lancaster, 1999). Once the couple has a biological child together, however, he may decrease investments in social children to concentrate them on his own biological offspring. Conversely, the presence of a mutual biological child in the mother's household may have spillover effects such that social children receive better care from their mother's partner than they would otherwise, as inequitable treatment of biological and social children in the same household may be more obvious and less acceptable to a mother than under-investment in a social child in a family in which there are no common biological children (Hofferth \& Anderson, 2003; Marsiglio, 2005).

Thus, it is unclear whether maltreatment risk for social children will vary by whether the family also includes a biological child of the resident parents. There is little empirical evidence on this issue. One study finds that among (particularly married) two-parent families, social children appear to experience higher quality parenting behaviors from their mother's partner if he has biological children with her (Hofferth and Anderson, 2003). However, the study does not examine CPS reports or parenting behaviors that could be classified as maltreatment.

\section{Single Mothers, Dating, and Cohabiting Relationships}

Compared to two-biological-parent families, single-mother families are likely to have higher rates of maltreatment given that, on average, they have fewer resources (i.e., time and money) to allocate to parenting, and also experience higher levels of stress (Amato, 2005). However, it is unclear whether families in which the mother is not romantically involved should have higher or lower maltreatment risk than those in which the mother is dating or cohabiting with a social father. On one hand, both daters and social fathers may make positive contributions to the family in the form of financial support, child care, and emotional support. On the other, they may be unwilling to make financial investments in unrelated children (for the reasons discussed above); their contact with children may provide opportunities for maltreatment; and they may draw away time and energy that mothers would have devoted to parenting in the absence of the relationship. On balance, then, children exposed to social fathers or daters could have higher or lower risk of maltreatment or CPS involvement than those in families in which the mother is not romantically involved. 
It is also unclear how children living with social fathers will fare relative to those exposed to daters. Social fathers can be expected to bring more financial resources into households than daters, but they will also have more contact with children. Thus, they will have more opportunities both to care for children and also to maltreat. Indeed, resident social fathers have been found to spend more time engaged with children than children's nonresident biological fathers (Anderson et al., 1999; Anderson, Kaplan, Lam, \& Lancaster, 1999). There is also likely to be a great deal of variation in involvement with children among daters, who may range from casual boyfriends who are not involved with the child or who, if they are involved, have no parenting authority, to longer-term boyfriends with some degree of parenting authority, and, finally, to partners who serve as a father figure (Marsiglio, 2004). On average, however, because daters are likely to spend less time and be less involved with children than social fathers, we may expect fewer opportunities for maltreatment in dating relationships than in cohabiting relationships. This lack of contact could offset low incentives to invest in unrelated children.

Analyzing the effects of maternal dating is also complicated in that mothers are sometimes involved in dating relationships with a biological father of one or more of their children. As biological fathers, these men may have greater incentives to invest in children than social fathers, but their status as "daters" may limit their access to children, and they may also have fewer incentives to invest in children than coresident biological fathers because they are less involved in their lives. Unfortunately, there are too few families in which mothers are dating biological fathers in our data to untangle these factors. However, because these men may differ from unrelated daters, we are careful to distinguish between these groups in our empirical work.

\section{Social Selection}

Associations between maternal relationship type and CPS involvement may reflect social selection in that they may be partially or fully attributable to differences in the characteristics of the individuals comprising particular family types. For example, mothers who are involved with men who are not their child(ren)'s biological father may be more likely to have characteristics which heighten risk for CPS involvement (e.g., low education and income, substance abuse, and mental health problems). Similarly, social fathers and men who date single mothers may have traits that elevate maltreatment risk (e.g., problems with violence, drugs, or alcohol), assuming that men with the most desirable qualities are likely to already be partnered. As such, we may observe greater CPS involvement when mothers are dating or cohabiting with social fathers than when they are living with their child(ren)'s biological father.

There is also likely to be selection into childbearing. Positive selection may occur if a mother is more likely to have additional children with a partner who has demonstrated high quality parenting behaviors with regard to her existing children than one who has not. It may also occur if men who have a greater interest in or commitment to parenting are more likely to have children with their partners. In such cases, we would expect more CPS involvement in families in which the father is not related to any children in the household than in those in which he is the biological father of some or all children. Conversely, there may be negative selection into childbearing such that individuals who engage in multi-partner fertility have characteristics (e.g., engage in less stable relationships) that are associated with poor parenting. In this case, we may expect higher rates of CPS involvement in families in which the male partner is the father of some of the children, relative to those in which he is the father of none or all of the children.

In the work that follows, we examine whether CPS involvement varies by whether children's mothers are romantically involved and, if so, by whether they are in a dating or cohabiting relationship with a man who is the father of all, some, or none of their children. We attempt to adjust for social selection by controlling for a host of background factors that may be associated 
with both family configuration and CPS involvement. These include demographic characteristics, behaviors of mothers and their partners, and measures of family resources.

\section{Method}

\section{Participants}

Our data are drawn from FFCW, a longitudinal cohort study of 4,898 children born between 1998 and 2000 in 20 U.S. cities (see Reichman, Teitler, Garfinkel, \& McLanahan, 2001, for a description of the sample and design). The study includes an over-sample of births to unmarried mothers. As such, sample families are more likely to be Black and Hispanic, to have absent biological fathers, and to have lower levels of income and education than those in a nationally representative sample. Nonetheless, the study is well-suited for our analyses as it includes a large and diverse sample of families with young children in low-income urban areas. Such families share many of the same characteristics as those that come to the attention of CPS.

FFCW families were interviewed in person at the time of the focal child's birth and by telephone when the focal child was approximately 1, 3, and 5 years old. Subsequent to the age 3 and 5 telephone interviews, they were asked to participate in an in-home assessment of parenting and child well-being. The in-home assessment conducted at age 5 included a set of questions about CPS involvement, including whether the family had been contacted by CPS since the focal child's birth, as well as the date of the family's most recent CPS contact. To be included in our analyses, a family must have had non-missing data on these items. We used multiple imputation techniques to impute missing data for all other variables. Specifically, following the strategy outlined in VonHippel (2007), we imputed values for all variables with missing data for the original FFCW sample of 4,898 , then deleted cases that had missing data on the outcomes prior to imputation. In all, we excluded 1,971 families that had missing data on the CPS measures. Of these, 1,881 were excluded because they did not participate in the 5-year FFCW core and/ or in-home interview. An additional 90 families participated in these interviews but were excluded due to missing data on one or both of the CPS-involvement items. This resulted in an analysis sample of 2,927 families. Imputation rates among the covariates ranged from $0 \%$ to $19 \%$; maternal relationship type was imputed for approximately $5 \%$ of families. We used ice software in Stata to impute five data sets and micombine software in Stata to conduct our analyses.

For $97 \%$ of the families in our analysis sample, the FFCW focal child's biological mother completed the age 5 in-home interview and, therefore, provided the CPS involvement data. For the remaining $3 \%$ of families $(N=84)$, someone else (usually the child's father or a grandparent) provided these data, presumably because the mother was not the primary caregiver at the time of the interview. To address concerns about the accuracy of the CPS involvement data in these cases, we checked the robustness of our results by estimating models excluding these 84 cases. Resulting estimates were consistent with those presented here.

\section{Measures}

CPS Involvement-Our primary outcome was a dichotomous variable $(1=y e s)$ for whether a family had been contacted by CPS between the 3-year FFCW core interview and the 5-year in-home assessment. This information was self-reported by the adult respondent to the age 5 in-home assessment. Families were coded "1" if the respondent reported the month and year that the family was most recently contacted by CPS to have occurred after the date of the family's 3-year core FFCW interview (the point at which maternal relationship type was reported). Families that had not been contacted by CPS since the focal child's birth and those that were contacted by CPS after the birth but only prior to the 3 -year core interview were coded "0". Because CPS is unlikely to contact a family regarding a "screened-out" child 
maltreatment report, this measure likely identifies families that were the subject of a CPS investigation or assessment. We refer to families responding affirmatively to this item as being CPS-involved.

This measure has three important limitations. First, it is self-reported rather than based on administrative records. This is problematic in that CPS involvement may be under-reported given the social stigma associated with child maltreatment. Nonetheless, our rate of selfreported CPS involvement is relatively high. For the (approximately) 5 -year period between the FFCW baseline core and age 5 in-home interviews, $10.4 \%$ of families reported CPS involvement; for the (approximately) 2-year period between the age 3 core and age 5 in-home interviews, $6.9 \%$ reported being contacted by CPS. These figures are comparable to rates obtained from administrative data for similarly disadvantaged populations (see, e.g., Berger \& Slack, 2006).

A second shortcoming of our primary measure is that it does not indicate which children were the participants of the CPS reports, which adults were the alleged perpetrators, or which types of maltreatment were alleged. However, for a family's most recent incident of CPS involvement, FFCW collected information about the nature of the alleged maltreatment and whether the alleged perpetrator was the mother or someone else. Below, we describe findings using this more detailed information. However, we were unable to precisely test whether associations between maternal relationship status and CPS involvement significantly differed by the type of maltreatment or the identity of the alleged perpetrator due to small cell sizes for those analyses.

Third, it is important to note that our outcome variable is not a direct measure of maltreatment. Although CPS involvement is a frequently-used indicator that a child has been maltreated or is at risk of maltreatment, it is subject to various types of biases and may miss some children who are maltreated while also including some who are reported in error (Waldfogel, 1998). Lacking population-based data on actual maltreatment, we used CPS involvement as the best available proxy. We also note that risk of CPS involvement is of interest in and of itself, as it is a consequential outcome from the perspective of both families and CPS.

Mother's Relationship Status-The key predictors in our analyses were 7 dichotomous variables indicating $(1=y e s)$ the mother's relationship status at the time of the age 3 core interview, including whether the mother was (a) living with (in a marital or cohabiting union) a romantic partner who was the biological father of all of the children in her household; (b) living with a romantic partner who was the biological father of some of the children in her household; (c) living with a romantic partner who was not the biological father of any of the children in her household; (d) dating a romantic partner who was the biological father of all of the children in her household; (e) dating a romantic partner who was the biological father of some of the children in her household; (f) dating a romantic partner who was not the biological father of any of the children in her household; or (g) not romantically involved. The reference category in our main models and those for two-parent families was that the mother was living with the biological father of all children in her household. The reference category for our models for single-mother families was that the mother was not romantically involved. Because only small fractions of mothers in our sample were dating the biological father of all (3.5\%) or some $(1.9 \%)$ children in their households, we were unable to draw conclusions about how these relationship types may be related to CPS involvement. Thus, although we present estimates for these relationship categories in the tables, we do not discuss these results in the text.

Covariates-In our main models, we controlled for four sets of covariates that may be associated with both maternal relationship type and CPS involvement. Basic demographics 
included the number of children and adults in the household at the time of the 3-year core interview, as well as dichotomous variables $(1=y e s)$ for Black, Hispanic, and other race/ ethnicity (with White serving as the reference category), and city of residence. Mother characteristics included maternal age and dichotomous variables indicating whether the mother's educational attainment was less than a high school degree, a high school degree, or more than a high school degree (reference category), as well as whether the mother worked in the week prior to the 3-year core interview. Family resources consisted of the logarithm of the family's permanent (mean) income from the year prior to the focal child's birth through the year prior to the age 3 core interview, a dichotomous variable indicating whether the family ever received Temporary Assistance for Needy Families (TANF) during that time period, and an index of family food insecurity at the time of the age 3 in-home assessment. Food insecurity was assessed on a 0 to 10 -point scale $(\alpha=.86)$ using the index developed by the U.S. Department of Agriculture (Bickel, Nord, Price, Hamilton, \& Cook, 2000). We standardized the measure to have a mean of 0 and a standard deviation of 1 . Maternal mental health and risky behaviors included measures of maternal depression and stress, as well as a dichotomous variable for whether the mother used alcohol, cigarettes, or drugs during her pregnancy with the focal child. Maternal depression was assessed using the Composite International Diagnostic InterviewShort Form (Nelson, Kessler, \& Mroczek, 1998), a 0 to 8-point index of depressive symptoms $(\alpha=.95)$. Maternal stress was assessed using the following four items: (a) being a parent is harder than I thought it would be; (b) I feel trapped by my responsibilities as a parent; (c) I find that taking care of my children is much more work than pleasure; and (d) I often feel tired, worn out, or exhausted from raising a family. Each item was scored on a 4-point scale for responses ranging from "strongly disagree" to "strongly agree"; items were then summed to create a total score $(\alpha=.64)$. We standardized the measures of maternal depression and stress to have a mean of 0 and standard deviation of 1 .

For some model specifications, we restricted our attention to two-parent families in which the mother was living with a man who was the biological father of all, some, or none of the children in her household. Because FFCW mothers provided data on the characteristics and behaviors of their coresident partners, we were able to include two sets of (biological or social) "father" controls in our analyses. Father characteristics included dichotomous variables indicating whether the father's educational attainment was less than a high school degree, a high school degree, or more than a high school degree (reference category), as well as whether he had ever been incarcerated, had a drug or alcohol problem, and had a physical or mental condition that limited his ability to work. Father behaviors were assessed by a mother-reported index of 12 items $(\alpha=.78)$ related to the father's treatment of her (e.g., "He expresses affection or love for you," "He slaps or kicks you"). Each item was scored on a 1- to 3-point scale ranging from "never" to "often" and reverse coded where appropriate, such that higher scores indicated higher quality behaviors. Our composite measure was comprised of a family's mean score across the 12 items, and was standardized to have a mean of 0 and a standard deviation of 1 . An appendix with detailed descriptions of all of the covariates and their construction is available from the authors.

\section{Empirical Strategy}

We used a series of probit regressions to estimate associations between maternal relationship type and CPS involvement. We first estimated probit models that did not adjust for any selection factors. We then examined the extent to which differences in CPS involvement by maternal relationship status could be accounted for by selection factors. To do so, we sequentially added controls for basic demographics (including city of residence), mother characteristics, family resources, and maternal mental health and behaviors to the model, and examined how the addition of each group of controls influenced the coefficients on the relationship type indicators. For the subsample of two-parent families, we also estimated variants of the model 
in which we sequentially added controls for (biological or social) father characteristics and behaviors. In the tables that follow, we present estimates of the marginal probability of CPS involvement that is associated with each maternal relationship type, relative to the mother living with the biological father of all children in her household. We also present results ( $p$-values from associated $\chi^{2}$ statistics) for two sets of Wald tests: (a) those testing the statistical equivalence of the marginal effects associated with various maternal relationship types, and (b) those testing the joint significance of each group of covariates. In supplemental analyses, we reestimated our models using logit regressions and confirmed that the results (not shown) were consistent with those presented here.

\section{Results \\ Descriptive Statistics}

Table 1 presents descriptive statistics for our sample. At the time of the age 3 core interview, approximately $61 \%$ of mothers lived with a male romantic partner or husband. Of these, about two-thirds were living with the biological father of all children in their household; the remainder were living with a partner who was not the biological father of at least one of these children. Of the $39 \%$ of mothers who were not living with a man, approximately $62 \%$ were not romantically involved and about $24 \%$ were in a dating relationship with a man who was not the father of any children in their household.

As noted above, $10.4 \%$ of sample families were contacted by CPS between their baseline core and 5-year in-home FFCW interviews and 6.9\% were contacted by CPS between their 3-year core and 5-year in-home interviews. However, the results in Table 1 indicate that CPS involvement varied considerably by maternal relationship type. Families that included the biological father of all children had the lowest rate of CPS contact. Families that included the biological father of only some children had higher rates of CPS involvement than those with a single mother who was not romantically involved.

The descriptive statistics in Table 1 also confirm that there are substantial differences in basic demographics, maternal characteristics, family resources, and maternal mental health and behaviors across families defined by these maternal relationship types. Mothers living with a man who was not the biological father of all children in their household were more likely to be Black (and less likely to belong to another racial or ethnic group) than those living with the biological father of all of their children. The former also tended to be younger, to have lower levels of educational attainment, and to have engaged in higher levels of risky behaviors during pregnancy; their families were poorer, more likely to have received TANF, and more likely to have been food insecure. In addition, single mothers, daters, and mothers living with a man who was not the biological father of any of their children reported more depressive symptoms, and single mothers and daters reported higher levels of stress, than those living with the biological father of all children. Finally, whereas mothers who were involved with men who were not the biological father of all of their children shared many characteristics with those who were not romantically involved, there were also notable differences between these groups in terms of family size, maternal age, family income, and TANF participation.

Among the subsample of two-parent families, we found fewer (and less consistent patterns of) differences in the characteristics of men who were the biological father of all, some, or no children. Men who were the biological father of some children had lower levels of education and were more likely to have been incarcerated and to have had a health or mental health condition that limited their ability to work than those who were the biological father of all children. Men who were not the biological father of any children had lower levels of education than those who were the biological father of all children. However, mothers reported that the former exhibited higher quality relationship-related behaviors toward them than did the latter. 


\section{Probit Analyses}

We first examined the extent to which CPS involvement was associated with maternal relationship type, without controlling for potential selection factors. Results for the full sample (column 1 of Table 2) indicated that families in which the biological father of all resident children was present in the household were the least likely of the family types of interest to have been contacted by CPS. Notably, however, among the other family types of interest we found only one significant difference: those that included the resident biological father of some of the children had more CPS contact than those with a nonromantically involved single mother.

As a robustness check, we estimated the basic model using alternative samples. We obtained similar findings when we used subsamples of two-parent (column 2 of Table 2) and singleparent (column 3) families. We also estimated a model in which we excluded families with fewer than two children (column 4). We did so because, by definition, one-child families cannot belong to the "lives with father of some" relationship category. As such, the coefficient for this category in our full sample model may have confounded the effects of family size and family structure. However, this restriction had little effect on our estimates.

We next investigated the extent to which selection factors accounted for variation in CPS involvement by maternal relationship type (Table 3). For ease of comparison, the first column of Table 3 simply repeats column 1 from Table 2 . Column 2 shows results when we added basic demographic controls to the model. The general conclusion drawn from the simpler model (column 1) - that families that do not include the biological father of all children are at greater risk of CPS involvement than all of the other family types of interest-was unchanged. The inclusion of mother characteristics (column 3 ) also made no difference. The inclusion of family resources (column 4) attenuated the coefficients of interest by an average of $26 \%$ (as compared to those in column 3). Nonetheless, all of the relationship type indicators of interest except that for "dating father of none" retained statistical significance. Likewise, controlling for maternal mental health and risky behaviors (column 5) produced an additional decline in the relationship type coefficients of about $17 \%$ (on average), but did not change our general conclusion.

After adjusting for the full set of selection factors, we found that families in which the biological father of only some of the resident children was present in the household were 6.4 percentage points more likely to be CPS-involved than those in which the resident biological father of all children was present (this difference had been 11.2 percentage points in the simplest model). Estimates for families that included a man who was not the father of any children and those with a single mother who was not romantically involved were attenuated from 10.7 to 6.7 and 6.1 to 3.3 percentage points, respectively, and the estimate for the mother dating a man who was not the father of any of the children in her household was no longer statistically different from zero. Finally, although the pattern of coefficients suggested that families with a resident biological father of some or no children had a higher likelihood of CPS involvement than those with a single mother who was either dating or not romantically involved, these differences were not statistically significant, potentially due to limited statistical power.

We next examined the effects of adding controls for men's characteristics in the subsample of two-parent families and found that doing so had little influence on our estimates. When we included all of the father characteristics and behaviors in the model (column 8), we found that families in which the mother lived with the biological father of some (none) of the children in the household were 4.4 (5.6) percentage points more likely to have had CPS contact than those in which the mother lived with the biological father of all children; these estimates were 4.8 (4.7) and 4.4 (5.4) percentage points in columns 6 and 7. As shown in Table 1, the characteristics of these men differed relatively little by relationship type. It is therefore not surprising that the inclusion of these controls had little effect on the results. Again, we note that the pattern of the coefficients suggested a larger increase in CPS involvement for families that included a man 
who was not the father of any of children than those that included the father of some children, although these effects did not significantly differ.

Extensions-We estimated several extensions to our primary models (results not shown). First, we estimated a series of models utilizing CPS involvement due to a particular type of maltreatment (physical abuse, neglect, and other forms of maltreatment excluding sexual abuse) as the outcome. Although the resulting estimates were smaller in magnitude and less precisely estimated than those of our primary models, their general pattern suggested that social father presence was associated with increased CPS involvement across maltreatment types, and particularly with regard to physical abuse. Second, we estimated separate models by whether the mother reported that she or someone else was the alleged maltreatment perpetrator. Associations between social father presence and increased CPS involvement were larger and more likely to be significant when the mother reported someone other than herself as being the alleged perpetrator. However, these results should be treated cautiously because of small cell sizes. Third, we estimated models for two-parent families in which we allowed associations between relationship type and CPS involvement to vary by the marital status of the mother and her partner. We found no significant differences in CPS involvement by marital status for any of the relationship types. Finally, we estimated models in which maternal relationship type was measured at the age 5 core interview (rather than the age 3 interview), as well as models in which the outcome included any CPS involvement that occurred after the focal child's birth (rather than after the age 3 in-home assessment). On the whole, our results were robust to these alternative specifications.

\section{Discussion}

Our findings supported our primary hypothesis: All other family types had a higher likelihood of CPS involvement than those in which the biological father of all children resided in the household. This result withstood the inclusion of a host of selection factors and was robust to alternative model specifications, with one exception: After adjusting for selection factors, we found no consistent evidence that maternal dating was associated with increased CPS involvement. In addition, although the overall pattern of results suggested a hierarchy such that families that included the biological father of some children were less likely to be CPS-involved than those that included a man who was not the biological father of any children, and that both of these family types had a higher likelihood of CPS involvement than those with a single mother who was dating a man who was not the father of any of her children or was not romantically involved, our point estimates sometimes had large standard errors, and none of these differences were statistically significant. Our supplemental analyses also revealed a relatively consistent pattern across models estimated using alleged physical abuse, neglect, and other maltreatment (excluding sexual abuse) as the CPS outcome, although only the physical abuse model produced significant effects. Finally, the associations between the presence of social fathers and CPS involvement were somewhat stronger when the alleged perpetrator was not the mother.

An important contribution of this study is that we were able to account for a wider range of potential selection factors than has been possible in prior research. Adjusting for these factors helped to ensure that our estimates did not reflect spurious associations driven by omitted variables. Interestingly, we found that adjusting for factors such as household size, race/ ethnicity, age, work status, and education — variables that have often been controlled in prior work-had relatively little effect on our estimates. Adjusting for both family resources and maternal mental health and risky behaviors - traits that have been omitted from most prior studies—-had a much larger effect on our estimates, attenuating them considerably. This highlights the importance of accounting for such characteristics and behaviors when attempting to understand relations between family type and child maltreatment. Indeed, a modest portion 
of these associations was linked to differences in the characteristics and behaviors of mothers selecting into particular family types, as mothers who lived with the father of all children in their household were, on average, more advantaged than other mothers. Nonetheless, these differences did not fully account for associations between family type and CPS involvement.

Among two parent families, we were also able to adjust for a wide range of father characteristics and behaviors. These factors have largely been omitted from prior studies. Of note, adjusting for them did little to explain associations between maternal relationship status and CPS involvement (after accounting for mother characteristics and behaviors), potentially because our data revealed relatively limited variation in father characteristics and behaviors across twoparent family types. Thus, these factors did little to explain why social father presence was associated with CPS involvement; net of mother and father characteristics and behaviors, social father families continued to have higher levels of CPS involvement than biological father families. This suggests that social father presence is associated with an elevated risk of CPS involvement not for reasons that are related to social fathers' characteristics or behaviors toward the child(ren)'s mother, but because these men are not the child(ren)'s biological father. We are unable to draw the same conclusion for daters given that our data did not include information on these men's characteristics and behaviors.

Our analyses have several limitations. First, our CPS measure was based on self-reported data. As discussed above, administrative data on CPS investigations among similarly disadvantaged samples suggest that there was not considerable under-reporting of CPS involvement in FFCW. However, self-report bias is nonetheless a concern, as is bias associated with which families come to the attention of CPS. Furthermore, our outcome measure assessed CPS involvement only over a 2-year period, and only for families that included a 3- to 5-year old child during that period (although these families may also have included children of other ages during the observation period), potentially limiting the generalizability of our results.

Second, our main outcome variable did not precisely identify the relationship between the alleged perpetrator and victim of abuse or neglect. Thus, although we found associations between social father presence and increased CPS involvement, we were unable to fully ascertain whether they were driven by maltreatment by mothers or their partners. As noted above, separate analyses of these associations for families in which the mother and someone other than the mother was the alleged perpetrator suggested that they were stronger among families in which the mother was not the alleged perpetrator than those in which she was. Although this may imply that associations between social father presence and CPS involvement are linked to these men's behaviors, we were unable to fully test this possibility in our data and are therefore unable to rule out other plausible explanations for this finding. For example, given that social father families may include step- and half-siblings, it is possible that increased CPS involvement will also reflect these children's behaviors. It is also possible that social father families are subject to greater levels of monitoring than biological father families, which may partially or fully explain differences in CPS involvement rates between these family types. Furthermore, bias in mothers' self-reports of the identity of the alleged maltreatment perpetrator may be of particular concern here. Future research would benefit from studies that more precisely identify the alleged perpetrators and their relationship to the children who are the subject of a CPS report or investigation. Future work should also attempt to identify the paths through which children who are exposed to social fathers are likely to come to the attention of CPS (e.g., whether as a result of their mother's behaviors or those of her partner) so that appropriate interventions can be developed to protect children who do not live with both of their biological parents.

Finally, despite our ability to account for a far wider range of covariates than has been possible in prior studies, as with all observational studies our estimates may have been biased due to 
omitted variables. As such, we are unable to rule out the possibility that families select into structures based upon factors that are unobserved in our data, but correlated with CPS involvement. Important omitted variables may include, but are not limited to, involvement of nonresident biological parents with children and the quality of these relationships, as well as the extent to which maternal relationships reflect stability or volatility. There may also be heterogeneity in associations of maternal relationship status with CPS involvement by factors such as child age and gender. Our analyses are silent in this regard.

\section{Conclusion}

Our results suggest that children living in single-mother families and families that include social fathers are at elevated risk of CPS involvement. Furthermore, the increased risk of CPS involvement associated with social fathers appears to be only partially due to social selection. As such, CPS agencies may be justified in viewing unrelated men's involvement in children's lives as a risk factor for maltreatment. Although we cannot conclude that such risk is greater for children living with a social father than for those living with a single mother (given that CPS involvement did not significantly differ between these two groups of families after accounting for the full set of covariates), it may nonetheless be important for CPS to devise appropriate interventions to address the presence and roles of social fathers in children's lives in order to promote children's safety. Most existing CPS interventions focus primarily on mothers. When they do involve men, they focus mainly on children's resident biological fathers and, to a lesser degree, on their resident stepfathers. In light of evidence that social fathers may place children at increased risk of maltreatment, however, CPS agencies should attempt to include and engage a wider range of men with whom mothers are romantically attached and to whom children are exposed. At the very least, CPS should work with mothers to minimize the potential dangers of children's exposure to unrelated men vis-à-vis child maltreatment, while also operating under the assumption that most unrelated men do not engage in child abuse or neglect.

\section{Acknowledgments}

We are grateful to Callie Langton for excellent research assistance and to Thu Vu for assistance with data management. We thank Maria Cancian and the editors and reviewers for helpful comments. The Fragile Families and Child Wellbeing Study is funded by NICHD grants R01HD36916 and R01HD41141, as well as a consortium of private foundations and other government agencies. This research is funded in part by NICHD grant K01HD054421.

\section{References}

Amato P. The impact of family formation change on the cognitive, social, and emotional well-being of the next generation. The Future of Children 2005;15:75-96. [PubMed: 16158731]

Adler-Baeder F. What do we know about the physical abuse of stepchildren? A review of the literature. Journal of Divorce and Remarriage 2006;44:67-81.

Anderson KG, Kaplan H, Lam D, Lancaster J. Paternal care by genetic fathers and stepfathers II: Reports by Xhosa High School students. Evolution and Human Behavior 1999;20:433-451.

Anderson KG, Kaplan H, Lancaster J. Paternal care by genetic fathers and stepfathers I: Reports from Albuquerque men. Evolution and Human Behavior 1999;20:405-431.

Berger, LM.; Slack, KS. Social fathers, marriage, and child protective services involvement: Evidence from the Illinois Families Study. University of Wisconsin-Madison; 2006. Manuscript

Bergstrom, TC. A survey of theories of the family. In: Rosenzweig, MR.; Stark, O., editors. Handbook of Population and Family Economics. New York: North Holland; 1997. p. 21-74.

Bickel, G.; Nord, M.; Price, C.; Hamilton, W.; Cook, J. Guide to Measuring Household Food Security, Revised 2000. Alexandria, VA: U.S. Department of Agriculture, Food and Nutrition Service; 2000.

Bumpass LL, Raley RK, Sweet JA. The changing character of stepfamilies: Implications of cohabitation and non-marital childbearing. Demography 1995;32:425-436. [PubMed: 8829975] 
Case A, Lin I, McLanahan S. How hungry is the selfish gene? Economic Journal 2000;110:781-804.

Cherlin A. Remarriage as an incomplete institution. American Journal of Sociology 1978;84:634-650.

Cherlin AJ, Furstenberg FF. Stepfamilies in the United States: A reconsideration. Annual Review of Sociology 1994;20:359-381.

Coohey C, Zhang Y. The role of men in chronic supervisory neglect. Child Maltreatment 2006;11:2733. [PubMed: 16382089]

Daly M, Wilson M. Discriminative parental solicitude: A biological perspective. Journal of Marriage and the Family 1980;42:277-288.

Daly M, Wilson M. Child abuse and other risks of not living with both parents. Ethology and Sociobiology 1985;6:197-210.

Daly, M.; Wilson, M. Homicide. New York: Aldine de Gruyter; 1988.

Emlen SL. The evolutionary study of human family systems. Social Science Information 1997;36:563589.

Furstenberg, FF.; Brooks-Gunn, J.; Morgan, SP. Adolescent Mothers in Later Life. New York: Cambridge University Press; 1987.

Furstenberg, FF.; Cherlin, A. Divided Families: What Happens to Children When Parents Part. Cambridge: Harvard University Press; 1991.

Giles-Sims J, Finkelhor D. Child abuse in stepfamilies. Family Relations 1984;33:407-413.

Hofferth SL, Anderson KG. Are all dads equal? Biology versus marriage as a basis for paternal investment. Journal of Marriage and Family 2003;65:213-232.

Lightcap JL, Kurland JA, Burgess RL. Child abuse: A test of some predictions from evolutionary theory. Ethology and Sociobiology 1982;3:61-67.

Malkin CM, Lamb ME. Child maltreatment: A test of sociobiological theory. Journal of Comparative Family Studies 1994;25:121-133.

Margolin L. Child abuse by mothers' boyfriends: Why the overrepresentation? Child Abuse \& Neglect 1992;16:541-551. [PubMed: 1393717]

Marsiglio W. Young nonresident biological fathers. Marriage and Family Review 2005;62:111-122.

Marsiglio, W. Stepdads: Stories of Love, Hope, and Repair. Lanham, MD: Rowman \& Littlefield; 2004.

Nelson, CB.; Kessler, RC.; Mroczek, D. Scoring the World Health Organization's Composite International Diagnostic Interview Short Form (CIDI-SF; v 1.0 Nov 98). Epidemiology, Classification and Assessment Group, World Health Organization; Geneva, Switzerland: 1998. Unpublished manuscript

Osborne C, McLanahan S. Partnership instability and child well-being. Journal of Marriage and Family 2007;69:1065-1083.

Radhakrishna A, Bou-Saada IE, Hunter WM, Catellier DJ, Kotch JB. Are Father Surrogates a Risk Factor for Child Maltreatment? Child Maltreatment 2001;6:281-291. [PubMed: 11675811]

Reichman N, Teitler J, Garfinkel I, McLanahan S. Fragile families: sample and design. Children and Youth Services Review 2001;23:303-326.

Rosenberg, J.; Wilcox, WB. Child Abuse and Neglect User Manual Series. Washington, DC: U.S. Department of Health and Human Services, Administration on Children, Youth, and Families, Office on Child Abuse and Neglect; 2006. The Importance of Fathers in the Healthy Development of Children.

Schnitzer PG, Ewigman BG. Child deaths resulting from inflicted injuries: Household risk factors and perpetrator characteristics. Pediatrics 2005;116:687-693.

Stiffman MN, Schnitzer PG, Adam P, Kruse RL, Ewigman BE. Household composition and risk of fatal child maltreatment. Pediatrics 2002;109:615-621. [PubMed: 11927705]

Von Hippel PT. Regression with missing Ys: An improved strategy for analyzing multiply imputed data. Sociological Methodology 2007;37:83-117.

Waldfogel, J. The Future of Child Protection: How to Break the Cycle of Abuse and Neglect. Cambridge: Harvard University Press; 1998.

Wilson, M.; Daly, M. Risk of maltreatment of children living with stepparents. In: Gelles, RJ.; Lancaster, JB., editors. Child Abuse and Neglect: Biosocial Dimensions. New York: Aldine De Gruyter; 1987. p. 215-232. 


\section{Biographies}

Lawrence M. Berger is an assistant professor of social work and a faculty affiliate of the Institute for Research on Poverty at the University of Wisconsin-Madison. His research focuses on the ways in which economic resources, socio-demographic characteristics, and public policies are associated with parental behaviors and child and family wellbeing.

Christina Paxson is a professor of economics and public affairs at Princeton University, and the director of Princeton's Center for Health and Wellbeing. Paxson has conducted research on a variety of topics related to children's health in both developed and developing countries. Her recent research focuses on the long-run effects of child health on economics outcomes in adulthood, and the effects of economic status on children's health and development.

Jane Waldfogel is a professor of social work and public affairs at Columbia University School of Social Work and a research associate at the Centre for Analysis of Social Exclusion at the London School of Economics. Waldfogel has written extensively on the impact of public policies on child and family well-being. Her current research focuses on work-family policies, inequality in early childhood care and education, and gaps in school achievement. 


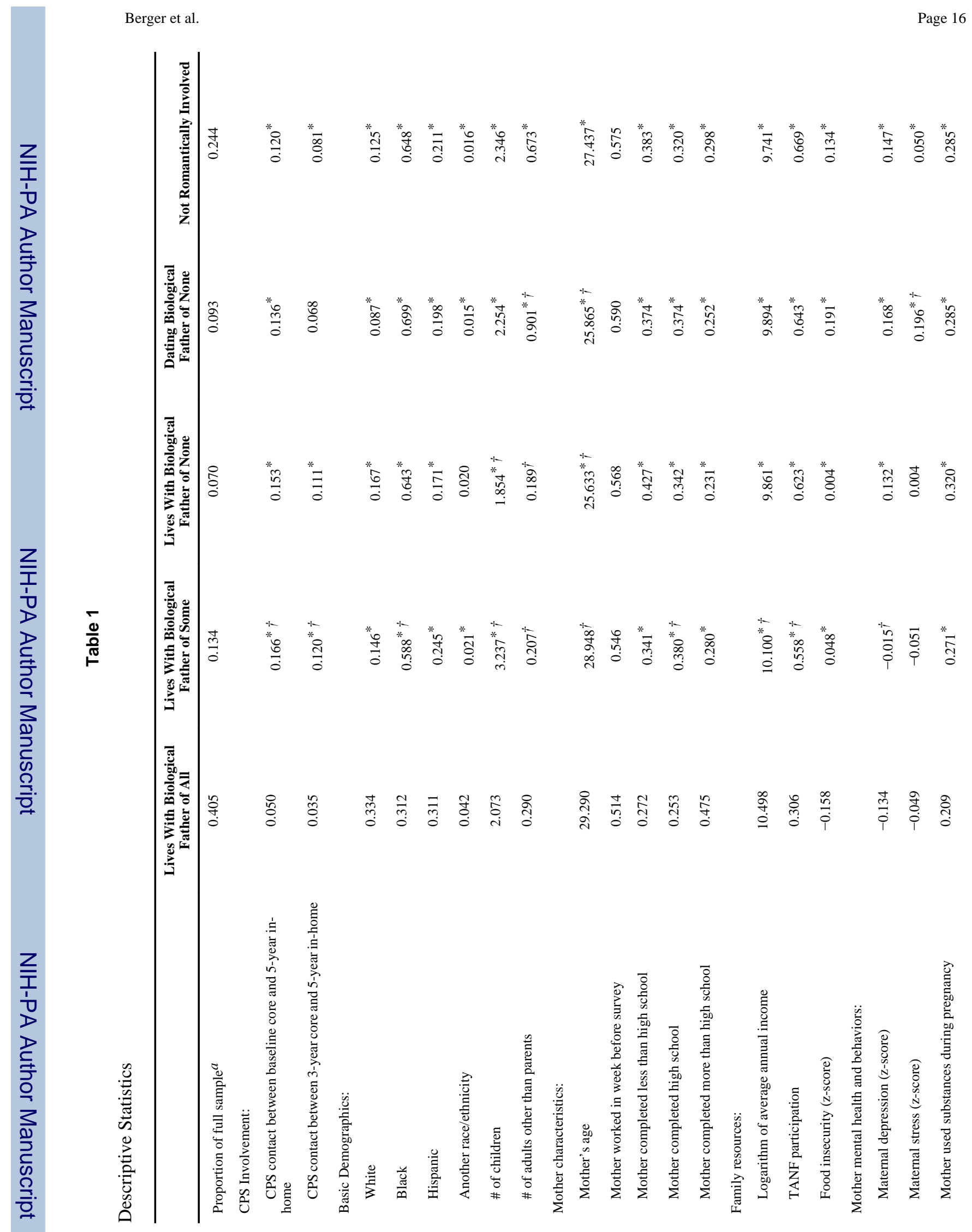

Child Maltreat. Author manuscript; available in PMC 2010 March 25. 
Berger et al.

Page 17

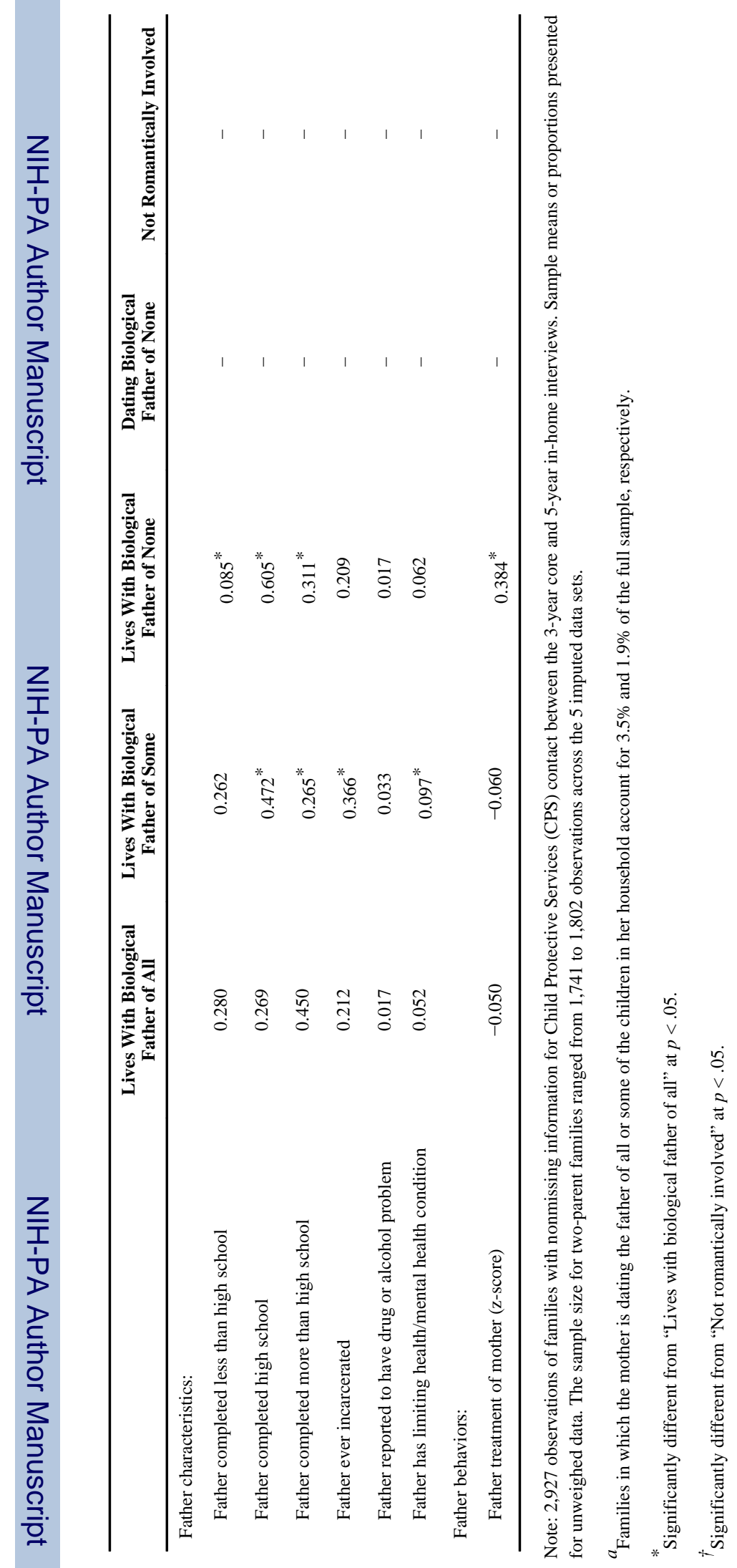

Child Maltreat. Author manuscript; available in PMC 2010 March 25. 
Table 2

Mother's Relationship Status and Child Protective Services (CPS) Involvement

\begin{tabular}{|c|c|c|c|c|}
\hline & (1) All Families & (2) Two-Parent Families & (3) Single-Parent Families & $\begin{array}{l}\text { (4) Families } \\
\text { With 2+ } \\
\text { Children }\end{array}$ \\
\hline Lives with father of some & $0.112^{* * *}(0.024)$ & $0.094^{* * *}(0.019)$ & & $0.103^{* * *}(0.025)$ \\
\hline Lives with father of none & $0.107^{* * *}(0.032)$ & $0.093^{* * *}(0.028)$ & & $0.116^{* *}(0.045)$ \\
\hline Dating father of all ${ }^{a}$ & $0.050(0.038)$ & & $-0.014(0.027)$ & $0.012(0.044)$ \\
\hline Dating father of some ${ }^{a}$ & $0.158^{*}(0.063)$ & & $0.064(0.048)$ & $0.148^{*}(0.064)$ \\
\hline Dating father of none & $0.049^{*}(0.024)$ & & $-0.014(0.019)$ & $0.045(0.031)$ \\
\hline Not romantically involved & $0.061^{* * *}(0.016)$ & & & $0.072^{* * *}(0.021)$ \\
\hline \multicolumn{5}{|c|}{ Wald tests of equality of the relationship status effects ( $p$-values for $\chi^{2}$ statistics): } \\
\hline $\begin{array}{l}\text { Lives with father of } \\
\text { some = lives with father of } \\
\text { none }\end{array}$ & 0.750 & 0.750 & & 0.952 \\
\hline $\begin{array}{l}\text { Dating father of none }= \\
\text { not romantically involved }\end{array}$ & 0.479 & & & 0.323 \\
\hline $\begin{array}{l}\text { Lives with father of } \\
\text { some = not romantically } \\
\text { involved }\end{array}$ & 0.040 & & & 0.224 \\
\hline $\begin{array}{l}\text { Lives with father of } \\
\text { none }=\text { not romantically } \\
\text { involved }\end{array}$ & 0.193 & & & 0.387 \\
\hline
\end{tabular}

Note: 2,927 observations. Marginal probabilities from probit regressions are shown in the table, with standard errors in parentheses. Analyses are unweighted. The sample sizes for two-parent families, single-parent families, and families with two or more children ranged from 1,741 to 1,802, 1,125 to 1,186 , and 2,081 to 2,099 observations, respectively, across the 5 imputed data sets. The reference group for the single-parent families model (column 3) was "not romantically involved." The reference group for all other models was "lives with father of all."

${ }^{a}$ We have little confidence in these estimates given that they are based on very small numbers of families. We therefore exclude them from our discussion of the results.

$$
\begin{gathered}
* x<.05 . \\
* * \\
p<.01 . \\
* * * \\
p<.001 .
\end{gathered}
$$


i $\dot{0} \dot{8}$

言. $\underset{*}{v} \stackrel{v}{*} \underset{*}{*}$ 